\title{
Finding a new drug and vaccine for emerging swine flu: What is the concept?
}

\author{
This article was published in the following Dove Press journal: \\ Biologics: Targets \& Therapy \\ 4 August 2009 \\ Number of times this article has been viewed
}

\section{Viroj Wiwanitkit}

Wiwanitkit House, Bangkhae, Bangkok 10160
Correspondence: Viroj Wiwanitkit Wiwanitkit House, Bangkhae, Bangkok 10160

Tel +66 24 I 32436

Email wviroj@yahoo.com
Abstract: Influenza is a well known infection of the respiratory system. The main clinical manifestations of influenza include fever, sore throat, headache, cough, coryza, and malaise. Apart from the well known classical influenza, there are also groups of influenza virus infections that are called "atypical infection". These infections are usually due to a novel influenza virus infection. In early 2009, an emerging novel influenza originating from Mexico called swine flu was reported. The World Health Organization noted a level VI precaution, the highest level precaution possible, for this newest influenza virus infection. As of June 2009, it is not known if this disease will be successfully controlled. Finding new drugs and vaccine for the emerging swine flu is still required to cope with this emerging worldwide problem.

Keywords: swine flu, drug, vaccine, concept

\section{Influenza infection Etiology}

Influenza is a well known infection. ${ }^{1,2}$ It is classified as a respiratory system infection. The main pathogenic cause of influenza is virus. The influenza virus is a widely studied virus in medicine. ${ }^{1,2}$ As a respiratory tract infection, the influenza virus is mainly transmitted via air as an airborne infectious disease. ${ }^{1,2}$ The pathogenic influenza virus can enter into the human body due to the inhalation of infectious air particles. ${ }^{3,4}$ The contaminated airborne particles can be generated by sneezing and coughing by infected patients. ${ }^{3,4}$ Specific body secretions that are highly contaminated with influenza virus include running nose fluids and saliva. It should also be noted that contaminated secretions can be found in spillage and in any used objects for up to two hours. ${ }^{3,4}$ If someone contacts the contaminated object, there is a possibility of infection and transmission of pathogen can be expected. Recently, Grayson and colleagues said that soap and water hand-washing or alcohol-based hand rub was highly effective in reducing influenza virus on human hands. ${ }^{15}$ Hand washing is an important practice to control the spread of influenza. ${ }^{5-8}$

\section{Clinical manifestations}

In general, influenza virus can be classified into three main groups, group A, group B, and group C. ${ }^{9,10}$ All groups can cause disease in human beings. Only group A can also cause infection in animals. Generally, patients usually develop signs and symptoms within two days (range 1-4 days) after contact with the pathogen. ${ }^{11,12}$ However, the isolation of influenza virus may not be seen, hence, transmission of disease can be 
possible before signs and symptoms are manifested. ${ }^{11,12}$ The peak of fever can be usually seen in day $3 .{ }^{11,12}$ The main clinical manifestations of influenza include fever, sore throat, headache, cough, coryza, and malaise. Due to the nature of the virus, the course of illness usually completes within one week or on day 9 after the first contact with the pathogen. Influenza complications usually start after this period. ${ }^{13}$ In general, the disease burden due to influenza is usually low. ${ }^{14,15}$ Hospitalization is usually required for two specific age groups: the infant group aged less than six months and the elderly group aged more than 65 years. Factors relating to the severity of influenza include age and underlying personal illness. The high-risk population for severe clinical manifestation includes the elder group aged more than 65 years, ${ }^{16}$ the infant group aged less than two years, ${ }^{17}$ patients with human immunodeficiency virus (HIV) infection, ${ }^{18}$ patients with chronic obstructive pulmonary disease and asthma, ${ }^{19}$ patients with congenital heart disease, ${ }^{20}$ patients on immunosuppressive drugs, and patients with prolonged usage of aspirin.

In the general low-risk adult population, the signs and symptoms of influenza can be self-limited. There is no need for medication. Serious complications ${ }^{21,22}$ can be seen, such as otitis media, pneumonitis, ${ }^{23}$ myocarditis, ${ }^{24}$ encephalopathy, ${ }^{25,26}$ and Reye's syndrome. ${ }^{27}$ As previously noted, the prevalence of complication is high in the at-risk groups. ${ }^{21,22}$ For example, up to $10 \%$ of infantile cases can develop complications and can end up with influenza encephalopathy. The rate of fatality in influenza encephalopathy is as high as one third of affected cases. $^{25,26}$

\section{Diagnosis, treatment, and prevention}

Clinical diagnosis is generally used for presumptive diagnosis. However, the main problem is due to the similarity between influenza and other respiratory tract infections. Laboratory investigation is required to confirm diagnosis. The basic immunological diagnosis is useful. ${ }^{28-38}$ However, a molecularbased diagnostic tool is usually required in atypical cases. ${ }^{39-45}$ This is because although the immunology-based technique is cheaper and faster in diagnosis, it lacks specificity. New molecular-based diagnostic tools can provide the most specific result since the diagnosis is based on the exact sequence of the viral particle. However, molecular-based diagnosis is expensive and time-consuming to perform. Therefore it might be unavailable and unaffordable for poor settings in developing countries.

Since the influenza viral infection can be self-limiting in otherwise healthy adults, there is no need for specific medication or treatment. ${ }^{46}$ However, in at-risk cases, an antiviral drug treatment is recommended. ${ }^{46-50}$ The widely used antiviral drugs for influenza are amantadine, ${ }^{51}$ rimantadine, ${ }^{52}$ oseltamivir, ${ }^{53}$ and zanamivir. ${ }^{54-56}$ Oseltamivir and zanamivir are newer drugs with a lower drug-resistant rate. These two drugs are also indicated for atypical cases.

At present, a specific influenza vaccine is available for prevention and is recommended for the at-risk population, especially the elderly. ${ }^{57,58}$ Jefferson and colleagues noted in a Cochrane review that influenza vaccines were effective in reducing cases of influenza, but were less effective in reducing cases of influenza-like illness. ${ }^{59}$ Jefferson and colleagues also noted that influenza vaccines had a modest impact on lost working days but there was no sufficient evidence on complications. ${ }^{59}$ In the scenario of an influenza pandemic, vaccination is the main hope for disease control. ${ }^{60}$

\section{Novel influenza virus infection: What is it?}

Apart from the already mentioned classical influenza virus infection, there are also a group of influenza virus infections that are called "atypical infection". These infections are usually due to a novel influenza virus infection. ${ }^{61,62}$ Those new pathogenic viruses, which usually result from genetic mutations, correspond to atypical infection. The new infection is usually recognized as a new emerging infectious disease. ${ }^{63}$

Zoonosis is usually mentioned for any novel influenza virus infection. "Why is zoonosis usually mentioned?" is an interesting question. As previously noted, influenza group A can infect both human beings and animals. When animals live near human beings, the exchange of viruses that each side carries can be expected and the final result can be a new, emerging zoonosis. This viral transmission scenario is a big problem for medicine since new emerging infections are new diseases that human beings have never experienced before.

The lack of immunity can be seen since present data indicate that only some older individuals have immunity against the current novel influenza A (H1N1) ${ }^{64}$ At present, most physicians are already aware of this ongoing pandemic.

Examples of emerging influenza are well known. The case of avian flu ${ }^{65-71}$ which emerged in the few recent years is the best example (Table 1). Avian flu is a novel influenza virus infection (owing to $\mathrm{H} 5 \mathrm{~N} 1$ influenza virus infection). This bird-borne disease is still a problem worldwide. ${ }^{65-72}$ No specific treatment has been developed yet. Luckily, only sporadic cases occurred around the world without pandemic. However, another emerging novel influenza originated from Mexico in early 2009. ${ }^{73-85}$ This new infection is called swine flu (Table 1). Swine flu is caused by the novel influenza virus, 
Table I Details of important novel influenza

\begin{tabular}{lll}
\hline Aspects & Avian flu' ${ }^{65-72}$ & Swine flu ${ }^{73-85}$ \\
\hline I. Pathogenic virus & H5NI influenza virus. & Atypical HINI influenza virus. \\
2. Related animal & Avian. & Swine. \\
3. Disease burden & High fatality. & No high fatality. \\
4. Pandemic & No. & Yes (in 2009). \\
5. Human to human transmission & No evidence. & Strong evidence. \\
6. Vertical transmission & No evidence. & No evidence. \\
7. Clinical manifestation & Similar to classical influenza & Similar to classical influenza with some interesting \\
& with some interesting atypical manifestations & atypical manifestations (such as nonfebrile illness). \\
8. Viral receptor in human beings & (such as diarrhea). & Can be seen in upper respiratory tract. \\
9. Vaccine & Can be seen in lower respiratory tract. & Has been manufactured and approved by the US FDA. ${ }^{86}$ \\
10. Treatment by antiviral drug & Not available. & Suggested, usually with oseltamivir, good outcomes. \\
& Needed, usually with oseltamivir, & \\
& but there are few good outcomes. & \\
\hline
\end{tabular}

Abbreviation: FDA, US Food and Drug Administration.

H1N1 influenza virus. The novel H1N1 influenza virus that causes swine flu is the result from genetic reassortment of gene segments from not only human H1N1 virus, but North American swine flu, Asian swine flu, and avian flu. ${ }^{87}$ This new recombinant virus causes the current pandemic and leads to generalized infection worldwide. ${ }^{85}$ In early June 2009, the swine flu, which is now called influenza 2009 is pandemic in many countries worldwide (more than 70 countries and more than 25,000 infected cases) ${ }^{85}$ The World Health Organization (WHO) noted a level VI precaution, the highest level precaution possible, for this newest influenza virus infection (Table 2). As of June 2009, it is not known if this

Table 2 Summary of some problematic points of swine flu infection ${ }^{73-85}$

\begin{tabular}{ll}
\hline Points & Descriptions \\
\hline I. Mode of transmission & Human-to-human transmission is confirmed. This raises serious concerns and leads to a high level of precaution set \\
by WHO. & A similar natural history to classical influenza can be seen. However, there is a notification on nonfebrile cases, \\
2. Natural history & Presently swine flu is worldwide. Thousands of infected cases can be seen. Of interest, in the early stage \\
& (April-May 2009) the disease was confined in Mexico and nearby countries. Some sporadic cases were observed \\
3. Epidemiology & This reflects the importance of traveler medicine. However, after the first period, human-to-human transmission \\
& becomes an important emerging issue. New infectious cases in distant countries with no history of traveling to the \\
problematic infected areas could be detected (such as in Japan and Thailand).
\end{tabular}

4. Diagnosis

Diagnosis by clinical manifestation shows difficulties in separating swine flu from classical influenza and other common respiratory tract infections. This is a serious problem for clinical diagnosis. The basic immunological diagnostic tool can confirm only HINI infection, but not typical or atypical. Molecular-based detection is required. A real-time PCR for diagnosis is available. However, the problems of over-register or under-diagnosis in setting due to lack of a gold standard can be expected.

5. Treatment Pharmacological treatment with oseltamivir is the present treatment, although it can not yet be confirmed if it is the best measure. With the present sign of emerging pandemic, there are several problems with the use of oseltamivir. These problems include the development of drug-resistant virus and availability as well as affordability for sufficient amounts of the drug in developing countries. Overlapping treatment of the classical strain to the new atypical strain can still be expected.

6. Vaccine Isolation, although possible, is not the best way to prevent contagion.Vaccination might be a more proper method. However, the present vaccine for classical influenza is not applicable to the new mutation of atypical swine flu. The development of a new vaccine specific for swine flu is needed and is the present focus of vaccinologists worldwide. As of early June 2009, there were some positive signals from some pharmaceutical companies on forthcoming specific vaccines for swine flu.

7. Complication The complications of swine flu are similar to those of classical influenza. This is the main problem that leads to some cases resulting in death, although not highly prevalent. Pneumonitis and respiratory failure are the most problematic and can cause poor outcome in complicated cases.

Abbreviations: PCR, polymerase chain reaction; WHO, World Health Organization. 
disease will be successfully controlled. Finding new drugs and vaccine for emerging swine flu is still required to cope with this emerging problem worldwide. This review focuses on the search for new drugs and a vaccine for swine flu. Data from searching all available publications from PubMed, Scopus, and ISI databases were included, and non-English language papers were excluded.

\section{Concepts on finding new drug for swine flu}

As previously noted, swine flu is an emerging disease. Treatments for swine flu are suggested and the general practice guideline for dealing with influenza is applied (Table 3). A routine antiviral for influenza is applied. Since amantadine and rimantadine are confirmed for drug-resistant strains of influenza, ${ }^{88-90}$ the recommended drugs are oseltamivir and zanamivir. In current general practice (Table 4), oseltamivir is routinely used in cases with swine flu with good efficacy. ${ }^{88-90}$ Focusing on the pharmacological reaction, oseltamivir blocks the $\mathrm{M} 2$ protein and blocks viral penetration and uncoating. ${ }^{91,92}$ According to an US report, no resistance to oseltamivir in the emerging swine flu was observed. ${ }^{88-90}$

However, new drugs for swine flu need to be sought. This need is due to several reasons. First, although oseltamivir is still effective, drug resistance is expected to develop in the near future due to a high volume of use in the pandemic scenario. Second, we can expect a genetic instability in the swine flu virus. In addition to new drugs, there is also a need for the local production of generic drugs of oseltamivir in developing countries. This issue needs to be carefully considered as drug patent concerns may be an obstacle for the local production of oseltamivir in many developing countries.

As previously mentioned, this paper will focus in the pharmacological dynamic issue of drug development and this paper does not discuss the current treatment process of swine flu. In order to find new drugs for swine flu, the recommended steps are listed below:

Table 3 Presently available antiviral drugs for influenza treatment

\begin{tabular}{llll}
\hline Drugs & $\begin{array}{l}\text { Specific site } \\
\text { of reaction }\end{array}$ & $\begin{array}{l}\text { Route of } \\
\text { administration }\end{array}$ & $\begin{array}{l}\text { Resistance } \\
\text { to swine flu }\end{array}$ \\
\hline Amantadine & M2 protein & Oral & Yes \\
Rimantadine & M2 protein & Oral & Yes \\
Oseltamivir & Neuraminidase & Oral & No \\
Zanamivir & Neuraminidase & Inhaled & No \\
Peramivir & Neuraminidase & Oral, intravenous & No \\
\hline
\end{tabular}

1. The viral sequence of the novel influenza virus must be mapped. Luckily, plenty of data are already loaded into public databases such as PubMed. At present, a diagnostic tool with real-time polymerase chain reaction (PCR) for influenza $\mathrm{A}$ is available and recommended as a diagnostic test by the US Food and Drug Administration (FDA). This provided several data on the genomics of the new emerging virus and helps further clarifies its viral structure. The data on sequence and structure of swine flu are useful not only for drug development, but also for diagnostic tool development.

2. The next focus should be on proven drugs. The reaction between the presently used drug, oseltamivir, and swine flu virus has to be clarified. This reaction has to be shown at the molecular level. Study by crystallization technique is suggested. Simulation by a moleculardocking technique can be helpful at this point. There are some present researches on this stage. ${ }^{93,94}$ According to the homology modeling of the neuraminidase, it can be seen that novel mutations are not likely to interfere with the active site hence the currently used neuraminidase inhibitors (oseltamivir, zanamivir, and peramivir) will still be effective against the new virus strain. ${ }^{94}$ The same mechanism of pharmacological reaction, blocking M2, can be seen in either classical or novel viruses. However, the drugs do not have the same effect in both viruses. This might be explained by the difference in required energy for drug-virus binding reaction. ${ }^{92}$ More required energy can be seen in case of the novel H1N1 influenza virus, which, based on the new viral genomic sequence, is larger than that of the classical virus. ${ }^{92}$

3. Possible genetic variation at the reaction site should also be predicted. This is useful for further calculation on optimum pharmacological binding energy between antiviral drug and virus. The mutated resistant portion should be the specific favorable site for our pharmacological target. Although a big genetic shift of the new virus has not yet been reported, it can be expected. Modification of previously used drugs into new drugs can be done based on the described data.

4. The derived drug needs to be tested in vitro and in vivo with a special focus on possible adverse effects including toxicity, mutagenesis, teratogenesis, and carcinogenesis. All drugs must pass and follow WHO recommendations with the four complete drug trial stages before becoming commercially available. This is needed to confirm that the drug is actually effective and pose no unwanted adverse effects. 
Table 4 Recommended dosage of oseltamivir and zanamivir in treatment and prevention for swine flu (adapted from World Health Organization recommendations, see http://www.cdc.gov/swine flu/recommendation.htm)

\begin{tabular}{lll}
\hline Drugs & Treatment & Prevention \\
\hline Oseltamivir* & $2 \mathrm{mg} / \mathrm{kg}$ bid $\times 5$ days & $2 \mathrm{mg} / \mathrm{kg}$ bid od $\times 10$ days \\
Zanamivir** & $10 \mathrm{mg}$ bid $\times 5$ days $* * *$ & $10 \mathrm{mg}$ od $\times 10$ days $* * *$ \\
& $10 \mathrm{mg}$ bid $\times 28$ days $* * * *$ & $10 \mathrm{mg}$ od $\times 28$ days $* * * *$ \\
\hline
\end{tabular}

Notes: *Either in cases with close contact to the patients or during the pandemic period; maximum dosage not more than $75 \mathrm{mg}$;**For patients aged more than 7 years; ****In cases with close contact to the patients; ****During the pandemic period.

\section{Concepts on finding new vaccine for swine flu}

Although there are several measures for prevention for swine flu including basic sanitation practice (handwashing and mask use), isolation, chemoprophylaxis, and vaccination, vaccination is expected to be the most effective tool. Although there is evidence on the finding of immunity to the new virus in some elderly adults, ${ }^{63}$ this might be a cross-protective immunity since there are some antigenic similarities to currently or previously circulating strains of influenza. ${ }^{94}$ There is currently no effective vaccine for swine flu. The classical influenza vaccine is not applicable. Finding a new vaccine for swine flu is the current hot topic in medicine. ${ }^{95}$ The current question is how to produce an effective pandemic influenza vaccine. ${ }^{96,97}$ Focusing on classical influenza, the problem of the genetic shift highlights the problem of the efficacy of the in-use influenza vaccine. In the case of the novel influenza swine flu, the problem remains. For production of pandemic influenza vaccine, the similar process to that of seasonal (regular) influenza vaccine can be followed. Nevertheless, adding to the basic two major focuses, safety and efficacy, for seasonal influenza vaccine, the other two major focuses, immunogenicity and timely availability, are also needed for pandemic influenza vaccine. ${ }^{94,95}$ However, the original seed virus must be the new virus. This raises the problem of production because it is hard to make the new virus available in huge amounts. The problem might be solved by present biotechnology, but the limitation of technology in developing countries also prevents success in local production of new vaccine in those settings. There are also post-production concerns: "How to test the new vaccine in the shortest period?" "How to register the new vaccine in each country?" "How to administer the vaccine to the at-risk population in each country?"

To find a new vaccine for swine flu, the recommended steps are listed below:
1. It will be necessary to completely map the genome of the novel influenza virus. This is the main requirement because any new vaccine has to be based on the genomic information of the new virus. Luckily, this data is presently available. The genomics data of the novel influenza virus is freely available on public databases such as PubMed. ${ }^{87}$ According to the recent study by Maurer-Stroh and colleagues, the antigenic regions of the neuraminidase relevant for vaccine development, serological typing, and passive antibody treatment was totally different from those of classical influenza. ${ }^{94}$ This is the main reason for asking why the vaccine for classical influenza cannot be applied for the novel strain and this is also the reason for the need for finding a new vaccine specific to the novel virus.

2. The immunological aspect of the new emerging virus must be known by finding the immunogenic part of the new virus. The use of immunomics technology might help shorten this period. The finding of the epitope is the basic primary step to find a new vaccine.

3. The application of new recombinant biotechnology to produce sufficient amount of new original seed virus for production of pandemic influenza vaccine must be completed. ${ }^{92,93}$

4. Post-production testing to assess both safety and efficacy of the derived vaccine is required. On one hand, the new vaccine has to be well verified before real world use. On the other hand, this process has to be as fast as possible to cope with the fast emerging pandemic.

5. Post-marketing surveillance to follow up the effectiveness and adverse effect of the new vaccine is needed, similar to the routine practice for all new vaccines.

As already noted, a new vaccine has just been manufactured and approved by the US FDA. ${ }^{86}$ However, it should be noted that there is still no report on the clinical and epidemiological aspect of the new vaccine is only in the trial phase. It is not possible to present the data on these aspects in this review. This information will be provided by future studies.

\section{Disclosure}

The author reports no conflicts of interest in this work.

\section{References}

1. Stamboulian D, Bonvehí PE, Nacinovich FM, Cox N. Influenza. Infect Dis Clin North Am. 2000;14(1):141-166.

2. Turkulov V, Madle-Samardzija N. Influenza - always present among us. Med Pregl. 2000;53(3-4):154-158.

3. Gapochko KG, Ogarkov VI. Experimental production of air-borne infections. Zh Mikrobiol Epidemiol Immunobiol. 1972;49(11):84-92. 
4. Tatem AJ, Rogers DJ, Hay SI. Global transport networks and infectious disease spread. Adv Parasitol. 2006;62:293-343.

5. Grayson ML, Melvani S, Druce J, et al. Efficacy of soap and water and alcohol-based hand-rub preparations against live H1N1 influenza virus on the hands of human volunteers. Clin Infect Dis. 2009;48(3): 285-291.

6. Simberkoff MS, Santos MR. Prevention of community-acquired and nosocomial pneumonia. Curr Opin Pulm Med. 1996;2(3):228-235.

7. American Academy of Pediatrics Committee on Infectious Diseases. Infection prevention and control in pediatric ambulatory settings. Pediatrics. 2007;120(3):650-665.

8. Carter JM. Hand washing decreases risk of colds and flu. J Natl Med Assoc. 2002;94(2):A11.

9. Maeda Y, Horimoto T, Kawaoka Y. Classification and genome structure of influenza virus. Nippon Rinsho. 2003;61(11):1886-1891.

10. Juozapaitis M, Antoniukas L. Influenza virus. Medicina (Kaunas). 2007;43(12):919-929.

11. Dowdle WR, Coleman MT, Gregg MB. Natural history of influenza type A in the United States, 1957-1972. Prog Med Virol. 1974;17: 91-135.

12. Robinson RQ. Natural history of influenza since the introduction of the A2 strain. Prog Med Virol. 1964;6:82-110.

13. Cox NJ, Subbarao K. Influenza. Lancet. 1999;354(9186):1277-1282.

14. Easing the burden: the challenge of managing influenza. Am J Manag Care. 2000;6(5 Suppl):S276-S281.

15. Gausset MF, Casadebaig F, Guillaud-Bataille JM, Quemada N, Terra JL. Mortality of mentally ill patients. Review of the literature. Encephale. 1992;18(1):93-100.

16. Yoshikawa TT. Important infections in elderly persons. West J Med. 1981;135(6):441-445.

17. Westcar $S$, Chantler T. Influenza: an overview with a paediatric focus. Community Pract. 2007;80(12):37-39.

18. Alagiriswami A, Cheeseman SH. Influenza and HIV: case report and review of potential interactions. AIDS Patient Care STDS. 2001;15(11):561-565.

19. Ferdinands JM, Mannino DM. Obstructive lung disease models: what is valid? COPD. 2008;5(6):382-393.

20. Lansdown AB. Viral Infections and diseases of the heart. Prog Med Virol. 1978;24:70-113.

21. Rothberg MB, Haessler SD, Brown RB. Complications of viral influenza. Am J Med. 2008;121(4):258-264.

22. Bro-Jørgensen K, Samuelsson IS. Influenza. Consequences for health and prevention. Ugeskr Laeger. 1989;151(40):2570-2574.

23. Ruben FL, Cate TR. Influenza pneumonia. Semin Respir Infect. 1987;2(2):122-129.

24. Sano T. Influenza myocarditis and pericarditis. Nippon Rinsho. 2006; 64(10):1916-1920.

25. Moreno-Flagge N, Bayard V, Quirós E, Alonso T. Acute encephalitis. Neuropsychiatric manifestations as expression of influenza virus infection. Medicina (B Aires). 2009;69(1):121-126.

26. Nobusawa E. Influenza encephalopathy and encephalitis. No To Hattatsu. 2000;32(2):142-147.

27. Wehinger H. Reye syndrome (author's trans1). Klin Padiatr. 1977;189(3):206-210.

28. Sullivan CJ, Jordan MC. Diagnosis of viral pneumonia. Semin Respir Infect. 1988;3(2):148-161.

29. Flewett TH. Rapid diagnosis of virus diseases. Br Med Bull. 1985;41(4):315-321.

30. Chaikka NA, Gorbachev EN. Use of the sensitized latex agglutination reaction for diagnosing viral infections. Vopr Virusol. 1985;30(5): 516-523.

31. Turner PA, Rytel MW. Diagnosis and management of viral infections. Compr Ther. 1984;10(6):20-29.

32. Voller A, Bidwell DE, Bartlett A. ELISA techniques in virology. Lab Res Methods Biol Med. 1982;5:59-81.

33. Frank AL. Selected laboratory aspects of influenza surveillance. Yale J Biol Med. 1982;55(3-4):201-205.
34. Schmidt J, Brunnemann H, Stelzner A, Süss J, Kittlick M, Oehring H. Virological diagnostics of acute respiratory diseases. Z Erkr Atmungsorgane. 1980;154(1):18-35.

35. Oswald NC, Jones MC, Yealland SJ. A review of routine tests for respiratory viruses in hospital inpatients. Thorax. 1975;30(4): 361-366.

36. Rytel MW. Rapid diagnostic methods in infectious diseases. Adv Intern Med. 1975;20:37-60.

37. Hofmann H. Modern virus diagnostics. Wien Med Wochenschr. 1973;123(49):725-729.

38. Pereira HG. Influenza: antigenic spectrum. Prog Med Virol. 1969; 11:46-79.

39. Mikhailovich V, Gryadunov D, Kolchinsky A, Makarov AA, Zasedatelev A. DNA microarrays in the clinic: infectious diseases. Bioessays. 2008;30(7):673-682.

40. Vernet G. Use of molecular assays for the diagnosis of influenza. Expert Rev Anti Infect Ther. 2007;5(1):89-104.

41. Ciçek C, Bilgiç A. Current approaches to the clinical virologic diagnosis of viral respiratory tract infections. Mikrobiyol Bul. 2003;37(2-3): 195-204.

42. Ellis JS, Zambon MC. Molecular diagnosis of influenza. Rev Med Virol. 2002;12(6):375-389.

43. Takahashi H. Recent progress in the diagnosis of respiratory disease: respiratory infection. Rinsho Byori. 2000;48(12):1130-1135.

44. Huang LM. Recent advances in the study, prevention, and treatment of infectious diseases. J Formos Med Assoc. 2000;99(2):92-99.

45. Shaw MW, Arden NH, Maassab HF. New aspects of influenza viruses. Clin Microbiol Rev. 1992;5(1):74-92.

46. Harper SA, Bradley JS, et al. Seasonal influenza in adults and children diagnosis, treatment, chemoprophylaxis, and institutional outbreak management: clinical practice guidelines of the Infectious Diseases Society of America. Clin Infect Dis. 2009;48(8):1003-1032.

47. Colman PM. New antivirals and drug resistance. Anпи Rev Biochem. 2009;78:95-118.

48. Hayden F. Developing new antiviral agents for influenza treatment: what does the future hold? Clin Infect Dis. 2009;48(Suppl 1):S3-S13.

49. Colman PM. A novel approach to antiviral therapy for influenza. J Antimicrob Chemother. 1999;44(Suppl B):17-22.

50. Laustsen G, Wimett L. Drug approval highlights for 2003. Nurse Pract. 2004;29(2):8-15, 19-21.

51. Takeuchi Y. Amantadine. Nippon Rinsho. 2003;61(11):1967-1974.

52. Hannoun C. Rimantadine in the prevention and treatment of influenza A. Rev Med Interne. 1988;9(5):554-558.

53. Schirmer P, Holodniy M. Oseltamivir for treatment and prophylaxis of influenza infection. Expert Opin Drug Saf. 2009;8(3):357-371.

54. Oxford JS. Zanamivir (Glaxo Wellcome). Drugs. 2000;3(4): 447-459.

55. Cheer SM, Wagstaff AJ. Spotlight on zanamivir in influenza. Am J Respir Med. 2002;1(2):147-152.

56. Caballero E, Prieto C, Ruiz M, Azanza JR. Zanamivir: new therapeutic option for influenza. Rev Med Univ Navarra. 2000;44(1):56-61.

57. Wiwanitkit $\mathrm{V}$. New respiratory virus (chicken pox, influenza and respiratory syncytial virus) vaccines: Efficacy, necessity and policy for tropical world at present. Hum Vaccin. 2009;5(9). [Epub ahead of print].

58. Jefferson T, Demicheli V. Influenza vaccination for elderly people and their care workers. Lancet. 2007;369(9576):1857-1858.

59. Jefferson TO, Rivetti D, Di Pietrantonj C, Rivetti A, Demicheli V. Vaccines for preventing influenza in healthy adults. Cochrane Database Syst Rev. 2007;2:CD001269.

60. Auewarakul P, Thongcharoen P. Vaccines for a potential influenza pandemic. Future Microbiol. 2007;2:345-349.

61. Forgie S, Marrie TJ. Healthcare-associated atypical pneumonia. Semin Respir Crit Care Med. 2009;30(1):67-85.

62. Kaji M. Influenza and other viral respiratory infections. Nippon Rinsho. 2003;61(11):1880-1885.

63. Cherkasskiî BL. New infections: myths and reality. Zh Mikrobiol Epidemiol Immunobiol. 2007;(3):111-116. 
64. Jeeninga RE, de Jong MD, Berkhout B. The New Influenza A (H1N1) Pandemic. J Formos Med Assoc. 2009;108(7):523-525.

65. Chan PK. A review on human influenza A H5N1 infections in Hong Kong. Sci China C Life Sci. 2009;52(5):412-418.

66. Khanna M, Kumar P, Choudhary K, Kumar B, Vijayan VK. Emerging influenza virus: a global threat. J Biosci. 2008;33(4):475-482.

67. Holst PJ, Christensen JP, Thomsen AR. Avian influenza and perspectives on vaccination against pandemic influenza. Ugeskr Laeger. 2008;24;170(48):3953-3956.

68. Ong A, Kindhauser M, Smith I, Chan M. A global perspective on avian influenza. Ann Acad Med Singapore. 2008;37(6):477-481.

69. Lupiani B, Reddy SM. The history of avian influenza. Comp Immunol Microbiol Infect Dis. 2009;32(4):311-323.

70. Pappaioanou M. Highly pathogenic H5N1 avian influenza virus: cause of the next pandemic? Comp Immunol Microbiol Infect Dis. 2009;32(4):287-300.

71. Guery B, Guidet B, Beloucif S, et al. Organization of intensive care in situation of avian flu pandemic. Arch Pediatr. 2008;15(12): 1781-1793.

72. Wiwanitkit V. No evidence of gynecological and obstetrical manifestation in H5N1 influenza virus infection. Arch Gynecol Obstet. 2009;279(4):609.

73. Wiwanitkit V. Obstetrical concern on new emerging swine flu. Arch Gynecol Obstet. 2009; May 24. [Epub ahead of print].

74. Naffakh N, van der Werf S. April 2009: an outbreak of swine-origin influenza $\mathrm{A}(\mathrm{H} 1 \mathrm{~N} 1)$ virus with evidence for human-to-human transmission. Microbes Infect. 2009;11(8-9):725-728.

75. Wang TT, Palese P. Unraveling the mystery of swine influenza virus. Cell. 2009;137(6):983-985.

76. While A. Swine flu: some good lessons learnt. Br J Community Nurs. 2009;14(6):270-275.

77. Nava GM, Attene-Ramos MS, Ang JK, Escorcia M. Origins of the new influenza $\mathrm{A}(\mathrm{H} 1 \mathrm{~N} 1)$ virus: time to take action. Euro Surveill. 2009;14(22). pii:19228.

78. Hayden EC. Avian influenza aided readiness for swine flu. Nature. 2009;459(7248):756-757.

79. Silversides A. Swine flu outbreak tests Canadian preparedness. CMAJ. 2009;180(12):E93-E94.

80. Kuntz-Simon G, Madec F. Genetic and antigenic evolution of swine influenza viruses in Europe and evaluation of their zoonotic potential. Zoonoses Public Health. 2009; May 29. [Epub ahead of print].

81. Opal SM. Swine flu, pandemics, and critical care. Crit Care. 2009; 13(3):146.
82. Castledine G. Swine flu panic is being spread by ignorance. Br J Nurs. 2009;18(10):651.

83. Mossad SB. The resurgence of swine-origin influenza A (H1N1). Cleve Clin J Med. 2009;76(6):337-343.

84. Cohen J. Swine flu outbreak. New details on virus's promiscuous past. Science. 2009;324(5931):1127.

85. Butler D. Swine flu attention turns to the tropics. Nature. 2009; 459(7246):490-491.

86. Collin N, de Radiguès X, Kieny MP; the World Health Organization H1N1 Vaccine Task Force. New influenza A(H1N1) vaccine: How ready are we for large-scale production? Vaccine. 2009; Jun 26. [Epub ahead of print].

87. Garten RJ, Davis CT, Russell CA, et al. Antigenic and genetic characteristics of swine-origin $2009 \mathrm{~A}(\mathrm{H} 1 \mathrm{~N} 1)$ influenza viruses circulating in humans. Science. 2009;325(5937):197-201.

88. Couzin-Frankel J. Swine flu outbreak. What role for antiviral drugs? Science. 2009;324(5928):705.

89. Centers for Disease Control and Prevention (CDC). Update: drug susceptibility of swine-origin influenza A (H1N1) viruses, April 2009. MMWR Morb Mortal Wkly Rep. 2009;58(16):433-435.

90. Centers for Disease Control and Prevention (CDC). Update: swine influenza A (H1N1) infections - California and Texas, April 2009. MMWR Morb Mortal Wkly Rep. 2009;58(16):435-437.

91. Schirmer P, Holodniy M. Oseltamivir for treatment and prophylaxis of influenza infection. Expert Opin Drug Saf. 2009;8(3):357-371.

92. Wiwanitkit V. Antiviral drug treatment for emerging swine flu. Clin Ther. 2009; 160(3):243-245.

93. Du QS, Wang SQ, Huang RB, Zhang DW, Chou KC. Insights from investigating the interaction of oseltamivir (Tamiflu) with neuraminidase of the 2009 H1N1 swine flu virus. Biochem Biophys Res Commun. 2009;386(3):432-436.

94. Maurer-Stroh S, Ma J, Lee RT, Sirota FL, Eisenhaber F. Mapping the sequence mutations of the $2009 \mathrm{H} 1 \mathrm{~N} 1$ influenza A virus neuraminidase relative to drug and antibody binding sites. Biol Direct. 2009;4:18.

95. Enserink M, Kaiser J. Swine flu outbreak. Devilish dilemmas surround pandemic flu vaccine. Science. 2009;324(5928):702-705.

96. Baras B, Bouveret N, Devaster JM, et al. A vaccine manufacturer's approach to address medical needs related to seasonal and pandemic influenza viruses. Influenza Other Respi Viruses. 2008;2(6): 251-260.

97. Saville M, Marsh G, Hoffenbach A. Improving seasonal and pandemic influenza vaccines. Influenza Other Respi Viruses. 2008;2(6): 229-235.
Biologics: Targets \& Therapy

\section{Publish your work in this journal}

Biologics: Targets \& Therapy is an international, peer-reviewed journal focusing on the patho-physiological rationale for and clinical application of Biologic agents in the management of autoimmune diseases, cancers or other pathologies where a molecular target can be identified. This journal is indexed on PubMed Central, CAS,

\section{Dovepress}

EMBase, Scopus and the Elsevier Bibliographic databases. The manuscript management system is completely online and includes a very quick and fair peer-review system, which is all easy to use. Visit http://www.dovepress.com/testimonials.php to read real quotes from published authors. 